\title{
Discussion on the Technique Teaching and Training of Stilts Racing
}

\section{Shubing Zhang}

\author{
NanChang Institute of Science and Technology, Nanchang, 330108
}

\author{
Keywords: Stilts racing; Technology; Teaching
}

\begin{abstract}
As atraditional sports event of ethnic minorities, stilts racing has drawn wide attention from all walks of life since it was listed as a competition project in the Seventh National Minority Traditional Sports Games. However, as a new competition project, it still needs to be further improved in the technical teaching and training method system. The basic methods and means of stilts racing teaching are discussed from the perspective of technical teaching and special quality training, combining some teaching methods and means in the process of teaching and training, reasonable and feasible teaching methods and means are sought to improve the sports performance and level of stilts racing.
\end{abstract}

\section{Introduction}

For a competition event, the technical action of stilts racing is not standardized. In the current arena games, a variety of styles of technologies are used, thus there is a big gap in the performance of the sport. Compared with other more maturecompetitive sports, stilts racing has its own characteristics in technical teaching and special training methods and means, but still has greater mining space. The basic methods and means of training for stilts racing are discussed combining the training methods and meansadopted by the author for the athletes during the preparation of the Municipality and the Provincial People's Games, to improve the athletic performance of stilts racing and sport level. Teaching and training methods for stilts sports skills learning and mastery are based on the formation of motor skills and human understanding of the law. According to its characteristics, training and technical teaching are improved.

\section{Stilts Sports}

The stiltsused in stilts racing are commonly known as "high horse" with alias of "Jimolie" (Tujia language). Athletes hold one stick with each hand and stamp the stirrup on the stick to race in the athletics field. The rank is determined by the time spent in the same distance. At first, it is a sport activity lovingly enjoyed by ethnic minorities in ethnic areas in Hunan Province. At the beginning, the "high horse" is used to prevent muddy water from wetting people's shoes and socks as a tool for migrating households in the rainy days. Later, it becomes a "transportation tool" for the students going to school in rainy days, then it's gradually developed into a traditional sports competition for ethnic minorities in racing and confrontation during festivals. Stilts racing hasgood economical effectiveness and pragmaticality, and is easy to popularize. Its equipment is simple, economical and effective, and can be made of two bamboo or tree fork; it's suitable for four seasons and is easy to carry out. It also has less demanding on the climate and venues, thus the young people like it very much. Stilts racing can develop students' flexibility and coordination and improve their strength of limbs and torso. At the same time, students' speed and speed endurance can be improved through training. Students' willpower and hard-working spirit can be cultivated. And the sport also has the features of skill and entertainment, thus it is a good event for young students' physical fitness and recreation.

\section{The Characteristic of Stilts Sport}

As a sport carried out in the athletic field, the technical requirements of stilts racing are more complex. It requires participants having good volitional qualities, including physical fitness and 
courage, perseverance. The most prominent feature of this sport is that the muscle movement reaches the maximum intensity, and the entire body is in a state of extreme tension, especially the process of excitement and inhibition of cerebral cortex should be quickly and frequently transformed and alternated. In the racing process, the body's sense of positioncan be effectively improved, which has a significant role on improving the balance of human body.

The features that stilts racing can be used to race stamina, skill and speed are exerted. And it's gradually developed into a folk sport - stilts racing. Because in this sport, bamboo is cut into horses, which is similar to taking bamboo instead of horses, so the sport is also known as bamboo horse. It is a competition of speed and strength on the high horse. In the competition, people's two legs stamp on the pedals of these two bamboo horses, moving forward or backward. The competition mainly includes racing and confrontation. Racing is to compete who is faster, which can be done on flat ground or athleticfield. Competition distance includes $50 \mathrm{~m}, 100 \mathrm{~m}, 200 \mathrm{~m}, 400 \mathrm{~m}$ and $4 \times 100 \mathrm{~m}$ relay run. Confrontation or the collision means that the athletes on their own bamboo horse use various offensive and defensive skills to knock down the other side and keep themselves on the bamboo horses within the stipulated fields, thus they are the winner. In addition to racing and confrontation, but stilts racing also includes off-road, obstacle and skill competitions. Off-road racing means the athletes race in the outskirts of the country, and they need to cross the river ditch, marsh or paddy fields, walk through the beach, get through grove and so on. The terrain includes uphill and downhill laces. Obstacle racing means several obstacles are set in the race way. Skill competition means the athletes on bigger bamboo horses compete who can have more postures on the bamboo horses, whose postures are more beautiful, as well as whose difficulty is higher under the condition of staying on the bamboo horses.

\section{Teaching and Training Method of Stilts Racing}

By watching the stilts racing teaching film, students have a good overview about the development of stilts racing and basic technology.

Teachers explain the action and demonstrate. The teaching should go step by step, from easy to difficult.

Leaning on the wall, "horse" stands by the wall or railings (wooden support). The athletes hold the upper end of the stilts bar with both hands, about 20 centimeters from the body, and then set foot on the tread, using the forefoot rather than foot arch. The body center of gravity should be move back appropriately. After standing steadily, the bottom end of the stilts should gradually move back, so that the center of body weight falls on the stilts bar. Then move the body center of gravity to maintain body balance.

Walk with the "horse" $\rightarrow$ walk away from the wall relying on the wall or railings (wooden support) to maintain body balance. Practice lifting the stilts in situ. Pay attention that the body should be upright, and eyes should look at the front horizontally. Take one or two steps forward, maintain balance, and lift the legs up and down, then lift and drop arms accordingly, but the movement range cannot be too big. The lifting of ipsilateral legs and arm should be coordinated.

The practitioner on the stilts holdsthe up end of the stilts and stand on the top of the stilts with the help of helper. The helper stands on the opposite side of the practitioner, holding the middle section of the stilts to help the practitioner maintain the balance and raise the stilts, raising legs march on the spot or move forward. Practitioners feel controlling the body center of gravity, lifting the leg muscle strength and the cooperation of legs and arms.

Use a variety of forms of teaching and practice, and fully mobilize the enthusiasm of students for practice.

Based on the way of practice, the racing can be divided into individual event and relay (oncoming relay, reciprocating relay) to practice or compete.

Based on the distance, it can be divided into 200 meters, 400 meters, $2 * 200$ meters, $2 * 400$ meters, $4 * 100$ meters, $4 * 200$ meters relay and $4 * 100$ meters oncoming relay and other forms of practice.

Based on the gender, it can be divided into men team, women team, and mixed team for practice. 
Based on the practice route, it can be divided into straight line, curve line, circular line practice.

Based on the practice direction, it can be divided into going forward, speed change, turning away and others slow practice and fast practice and gradually over to jogging, running.

\section{Psychological Training}

As a competitive sport having higher requirements for human's body balance, muscle control strength, it's a little difficult for beginners to study stilts racing, because people's feet stamp on the tread of the "horse" with arms on the same side swinging at the same time to complete the movement. The balance of body depends on two "horse" feet, but "horse" feet support area is small, so riding in the "horse" is difficult to maintain body balance. Therefore, athletes should not only have good psychological qualities, responsive, lively personality, self-confidence, ambitious heart, but also have hardworking, indomitable fighting spirit, and are able to withstand fierce competition and have good affordability.

During training, more competition opportunities can be created for athletes through various competitions so as to enhance the enthusiasm of team members in practice, at the same time, improve their sensitivity of movements and enhance their balance ability so that team members can appreciate the intenseness and tension of the competitions, as well as the arduous task, thus developing their good psychological quality.

\section{Conclusion}

In the sports development process of the world, all the modern competitive sports sweeping the world are developed from the national sports. China has 56 nationalities. The quantity of ethnic sports and their colorful forms can be said to be the greatest in the world. They are an integral part of our Chinese civilization, so we must give protection and carry forward their development. China's national sports still need to follow the only way in the initial stage --- getting into the school. On the basis of teaching practice, this paper analyzes the technique of stilts racing comprehensively and focuses on the teaching and training of stilts racing. The purpose is to make the teaching of stilts into the textbook and promote better in school.

\section{References}

[1] Dong-Fu X U, Zhang B H. Analysis of the Factors Influencing the Speed in the Short Distance Events of High-foot Racing[J]. Journal of Xichang College, 2011.

[2] Goldberg K. It's a footrace: NBA stars let shoe companies build profits from ground up.(Sports)(Sports Life) $[\mathrm{J}]$.

[3] Mccaw R U. McCaw hid extent of World Cup foot injury[J]. Racing \& Sports.

[4] Milmo C. Foot-and-Mouth Crisis: Angry Farmers Fear Losing out as Racing Resumes out ; Sport[J].

[5] Connaughton B, Mick. RACING: Nine New Tracks Fly the Flag for Point-to-Points ; A Sport Halted by Foot-and-Mouth Disease Starts a Fresh Season This Weekend[J]. Contract Journal, 2005.

[6] Ssociation A B. Gainesville, Florida: A Circle of Diversity[J].

[7] Lee T J M. Feature extraction and classification of skiing/snowboarding jumps with an integrated head-mounted sensor[J]. 2015.

[8] Slate E H. Bayesian Modeling of Footrace Finishing Times : Journal of Quantitative Analysis in Sports[J]. 2010.

[9] Why are things heavy The Higgs Boson might have a. Why are things heavy? The Higgs Boson might have $\mathrm{a}[\mathrm{J}]$. Totse Com.

[10] Joiningdots P O. There's another thing that last picture shows tha[J]. Energy Costs Will Soar.

[11]Breine B, Malcolm P, Frederick E C, et al. Relationship between running speed and initial foot contact patterns.[J]. Medicine \& Science in Sports \& Exercise, 2014, 46(8):1595-603.

[12] Salarpur. India's inaugural F1 race: speeding past the poor[J]. 2015. 